\title{
Predicting responses of the Adélie penguin population of Edmonson Point to future sea ice changes in the Ross Sea
}

\author{
Tosca Ballerini ${ }^{1,2,3}$, Giacomo Tavecchia ${ }^{4}$, Francesco Pezzo ${ }^{1,5}$, Stéphanie Jenouvrier ${ }^{6,7}$ and \\ Silvia Olmastroni ${ }^{1,8}$
}

${ }^{1}$ Dipartimento di Scienze Fisiche, della Terra e dell'Ambiente, Università degli Studi di Siena, Siena, Italy

${ }_{2}^{2}$ Mediterranean Institute of Oceanography (MIO), University of Toulon/Aix-Marseille University, CNRS/INSU, IRD, MIO, UM 110, La Garde Cedex, France

${ }^{3}$ Mediterranean Institute of Oceanography (MIO), Aix-Marseille University/University of Toulon, CNRS/INSU, IRD, MIO, UM 110, Marseille, Cedex, France

${ }^{4}$ Population Ecology Group, Institut Mediterrani d'Estudis Avançats (IMEDEA), CSIC-UIB, Mallorca, Spain

${ }^{5}$ Museo di Storia Naturale della Maremma, Strada Corsini, Grosseto, Italy

${ }^{6}$ Biology Deptartment, Woods Hole Oceanographic Institution, Woods Hole, MA, USA

${ }^{7}$ Centre d'Etudes Biologiques de Chizé, Centre National de la Recherche Scientifique, UPR1934, Villiers en Bois, France

${ }^{8}$ Museo Nazionale dell'Antartide, Siena, Italy

\section{Edited by:}

Morten Frederiksen, Aarhus

University, Denmark

\section{Reviewed by:}

David Ainley, H.T. Harvey \&

Associates, USA

Virginie Rolland, Arkansas State

University, USA

\section{*Correspondence:}

Tosca Ballerini, Mediterranean Institute of Oceanography (MIO), Université de Toulon, Aix-Marseille Université, CNRS/INSU, IRD, MIO, UM 110, La Garde Cedex 83957,

France

e-mail: toscaballerini@gmail.com; tosca.ballerini@mio.osupytheas.fr
Atmosphere-Ocean General Circulation Models (AOGCMs) predict changes in the sea ice environment and in atmospheric precipitations over larger areas of Antarctica. These changes are expected to affect the population dynamics of seabirds and marine mammals, but the extent of this influence is not clear. We investigated the future population trajectories of the colony of Adélie penguins at Edmonson Point, in the Ross Sea, from 2010 to 2100 . To do so, we incorporated the relationship between sea ice and demographic parameters of the studied colony into a matrix population model. Specifically, we used sea ice projections from AOGCMs and a proxy for snowfall precipitation. Simulations of population persistence under future climate change scenarios showed that a reduction in sea ice extent (SIE) and an increase in precipitation events during the breeding season will drive the population to extinction. However, the population growth rate estimated by the model was lower than the population growth rate observed during the last decades, suggesting that recruits from other colonies maintain the observed population dynamics at Edmonson Point. This local "rescue" effect is consistent with a metapopulation dynamic for Adélie penguins in the Ross Sea, in which neighboring colonies might exhibit contrasting population trends and different density-dependent effects. In the hypothesis that connectivity with larger source colonies or that local recruitment would decrease, the sink colony at Edmonson Point is predicted to disappear.

Keywords: climate change, environmental stochasticity, IPCC, matrix population models, metapopulation dynamics, population growth, seabirds

\section{INTRODUCTION}

In the Southern Ocean, the disappearance of the sea ice habitat associated with climate change threatens the viability of seabird and marine mammal populations (Fraser et al., 1992; Jenouvrier et al., 2005, 2009, 2012; Barbraud and Weimerskirch, 2006; Siniff et al., 2008; Forcada and Trathan, 2009; Ainley et al., 2010; Trivelpiece et al., 2011) because their life cycles and life-history strategies evolved in response to a sea ice habitat that was stable and predictable over large spatial and temporal scales (Forcada et al., 2008). The Adélie penguin (Pygoscelis adeliae) is one of the species that has been affected the most by changes in sea ice extent (SIE) and sea ice concentration (SIC) linked to increased air and sea temperature (Ainley, 2002; Ainley et al., 2010). This species uses sea ice as a resting platform in the winter period (Ainley, 2002). Sea ice is also the habitat for Adélie penguins' principal preys, such as the krill (Euphausia spp.) and the Antarctic silverfish (Pleuragramma antarcticum).

Satellite data on sea ice characteristics are available for Antarctic since late 1970s (Cavalieri et al., 2003). They show a decrease in SIE, SIC, and duration of the winter sea ice season in the western Antarctic Peninsula region (Kwok and Comiso, 2002; Zwally et al., 2002; Stammerjohn et al., 2008, 2012) and an increase in SIE and in the size of the Ross Sea polynya (an area of permanent open water within the sea ice) in the Ross Sea sector of the Southern Ocean (Parkinson, 2002; Zwally et al., 2002; see also Ainley et al., 2010).

These changes in the sea ice habitat affected the Adélie penguin populations (Ainley et al., 2010). Census of Adélie penguin breeding populations began around 1950s (Croxall et al., 2002) and showed a decrease in the size of Adélie penguin population along the Western Antarctic Peninsula and the Scotia Sea region, but an increase in the Ross Sea sector (Smith et al., 1999). The negative trend of penguin populations in the Western Antarctic Peninsula/Scotia Sea region has been thought to be a consequence of the loss of sea ice habitat caused by the rapid increase of air and sea temperature (Fraser et al., 1992; Smith et al., 1999; Ducklow et al., 2007; Hinke et al., 2007; Forcada and Trathan, 2009; Lynch et al., 2012). In addition to the negative effects of decreased SIE, 
penguin populations in the Western Antarctic Peninsula/Scotia Sea region have also been affected by the increased snowfall and water melt runoff (Trivelpiece and Fraser, 1996). The opposite positive trend in the Ross Sea is presumably the consequence of the increase in SIE and the size of the Ross Sea polynya that supposedly facilitated access to breeding colonies on land (Ainley et al., 2005, 2010). These contrasting trends in Adélie penguin population dynamics at different geographic locations in the Southern Ocean are explained by a habitat optimum model (Fraser and Trivelpiece, 1996; Smith et al., 1999) that relates population growth to the frequency of years with extensive winter sea ice. According to the model, either too much or too little winter SIE and SIC negatively affect penguin population growth (Fraser and Trivelpiece, 1996; Smith et al., 1999; Ainley et al., 2010). Winter SIE affects survival rates (Wilson et al., 2001; Jenouvrier et al., 2006; Ballerini et al., 2009; Emmerson and Southwell, 2011), and summer sea ice conditions close to breeding colonies influence breeding success (Olmastroni et al., 2004a; Emmerson and Southwell, 2008).

Global climate models developed by the Intergovernmental Panel on Climate Change (IPCC; Meehl et al., 2007) predict a decline of SIE and SIC all over Antarctica by the end of the century, even in the Ross Sea where SIE has so far increased (Ainley et al., 2010). Climate models also predict a robust increase in snowfall precipitations in Antarctica in the coming century with the possibility of intensification of extreme atmospheric events (Meehl et al., 2007; Turner et al., 2009). The majority of the studies on Adélie penguin population dynamics and sea ice are based on census of total population size (cfr. Fraser et al., 1992; Smith et al., 1999; Wilson et al., 2001; Ainley et al., 2005; Forcada et al., 2006; Hinke et al., 2007). However, studying the whole life cycle and the effects of a changing environment on vital rates is essential to understand the mechanisms that allow birds to respond to climate change ( $\AA$ dahl et al., 2006; Jenouvrier, 2013; Oli, 2014).

Here, we used demographic data collected at the individual level during the breeding seasons 1994-2004 at the colony of Edmonson Point, Central Victoria Land coast, Ross Sea (Figure 1), to build a matrix population model (Caswell, 2001) for the Adélie penguin. First, we compared the growth rate projected from the demographic model to the growth rate measured from ground census. Then we used the model to project population growth using future projections of SIE obtained form IPCC-class climate models (Jenouvrier, 2013). To investigate cross-seasonal effects (Ward et al., 2005) we also built environmental scenarios that are based on the assumed causation between unusually harsh weather conditions at the breeding site (Olmastroni et al., 2004a) and increased mortality in the following winter despite "good" sea ice conditions (Ballerini et al., 2009).

\section{MATERIALS AND METHODS STUDY POPULATION AND DEMOGRAPHIC DATA}

The colony of Edmonson Point $\left(74^{\circ} 21^{\prime} \mathrm{S}-165^{\circ} 10^{\prime} \mathrm{E}\right)$ is situated in the Wood Bay, a large embayment covered by fast ice (persistent sea ice that keeps in place for several years), along the Victoria Land cost in the Ross Sea (Figure 1). Edmonson Point

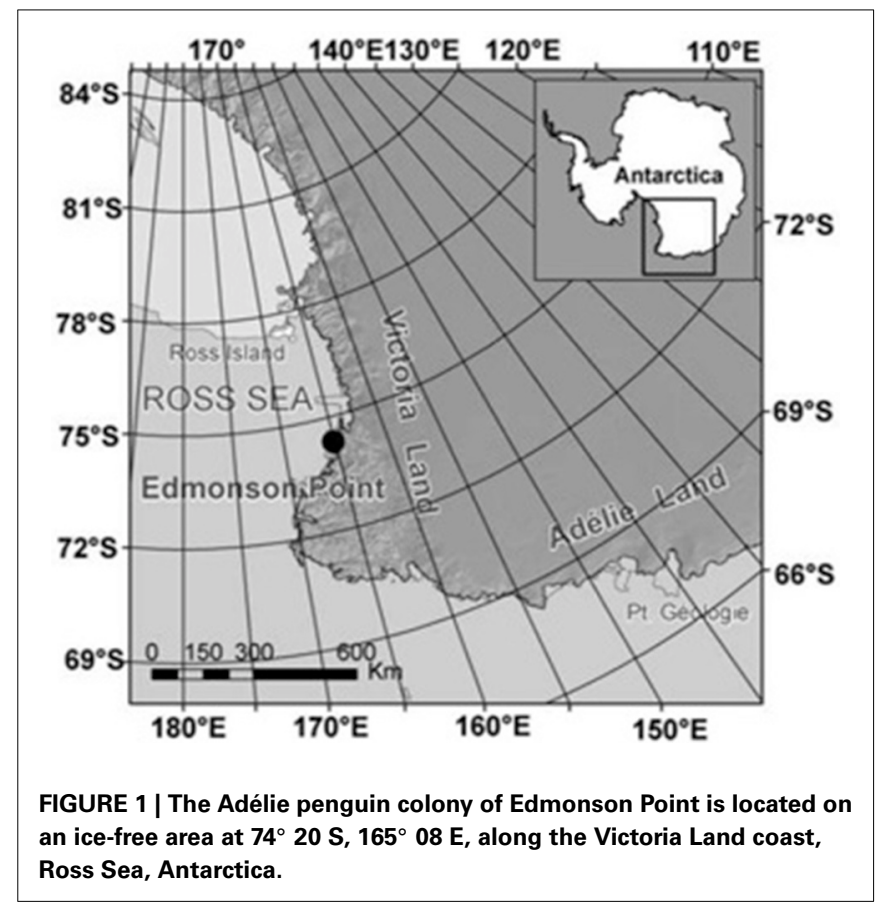

has been a nesting site for Adélie penguins since 3000 BP (Baroni and Orombelli, 1994). Today the colony is composed of several (10-13) breeding groups (hereafter "subcolonies") where population size was assessed by ground counts in 13 seasons during the period 1993-2009 (Olmastroni et al., 2000; Pezzo et al., 2007; this study). From 1994 to 2004 two of the subcolonies have been the focus of an intensive study of individual-based information on marked animals and nests (Supplementary Material, Table A1; Olmastroni et al., 2000). Each year, birds implanted with passive transponders (TIRIS tag) were reobserved in the study area through an Automatic Penguin Monitoring System and through manual observations (Olmastroni et al., 2000). Their capture histories were used to get estimates of age- and time-dependent survival probabilities for this population (Ballerini et al., 2009). Nests were monitored daily from the beginning to the end of the breeding season to calculate annual values of clutch size, hatching success and creching success (Pezzo et al., 2007) according to the CCAMLR Ecosystem Monitoring Program (cfr. SC-CCAMLR, 2004). Daily observations of breeding nests also allowed estimation of the percentage of eggs and chick mortality due to weather factors (Olmastroni et al., 2004a) and skua predation. The demographic parameters measured during the study period were used to create a time-invariant and a time-dependent dataset used in the demographic analyses.

\section{LIFE CYCLE AND MATRIX POPULATION MODEL}

We combined the available survival (Ballerini et al., 2009) and fecundity parameters (Pezzo et al., 2007) collected at the colony of Edmonson Point into a closed, pre-breeding, age-structured model for the Adélie penguin (Figure 2). The model considers females only and the projection interval is from November at year $t$ to November at $t+1$. Following Ballerini et al. (2009), the model has five age classes. New individuals result from the 
combination of breeding propensity $(b p)$, female fecundity $(f)$ and survival during the first year of life $(s 0)$. Fecundity $(f)$ is defined as the product of clutch size (cs), hatching success ( $h s)$ and fledging success $(f s)$. Age-at-first reproduction varies in the Adélie penguin (Ainley, 2002), but precise estimates are not available for penguins at Edmonson Point, where all breeding birds were assumed to be $4+$ (Ballerini et al., 2009). Transitions between ageclasses are represented by a structured matrix population model, A, that includes fecundity and survival estimates for each age class considered (Caswell, 2001) as:

$$
\mathbf{n}(t+1)=\mathbf{A}(t) \mathbf{n}(t)
$$

where $\mathbf{n}(\boldsymbol{t})$ is a vector with the number of birds for each age at time $t$ and the matrix $\mathbf{A}(t)$ projects the population from $t$ to $t+1$. The population growth rate $(\lambda)$ was calculated as the dominant eigenvalue of the matrix $\mathbf{A}$, while the stable age distribution, $\mathbf{w}$, is the dominant right eigenvectors of $\mathbf{A}$. In the initial population vector $\mathbf{n}(\mathbf{1})$ the number of individuals in each age class was scaled according to the stable age distribution $\mathbf{w}$ obtained from $\mathbf{A}$ with average parameters over the study period.

\section{FITNESS LANDSCAPE}

The population growth rate $(\lambda)$ estimated by the matrix model was lower than the population growth rate derived from ground census (see Results). Previous studies indicated that the values of breeding success (0.76 chicks/nest, Pezzo et al., 2007) and firstyear survival (0.34, Ballerini et al., 2009) estimated for the colony of Edmonson Point are lower than in other penguin populations. But while the value of breeding success is robust because obtained from individually monitored nests and from ground census, firstyear survival might be underestimated (Ballerini et al., 2009). First-year survival for the population of Edmonson Point was estimated based on resightings of marked birds in the intensive study area. While Adélie penguins have strong return rates to their natal colony (Sheperd et al., 2005), it is possible that birds

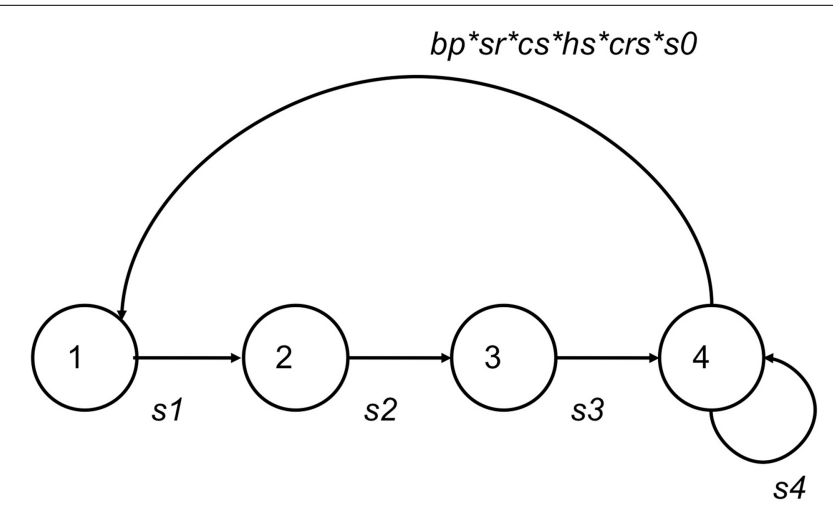

FIGURE 2 | Adélie penguin life cycle graph. $s_{i}$ is the probability that an individual in stage $i$ survives from time $t$ to time $t+1$; $b p$ is the probability, conditional on survival, that an individual in stage $i$ breeds; $s r$ is the assumed sex-ratio at birth; $c s$ is clutch size; $h s$ is the probability of an egg to hatch; crs is the probability of a chick to survive until the crèche stage. The graph corresponds to the matrix population model (Equation 1) (see Methods section). marked as chicks in the intensive study area settled as breeders in other subcolonies of Edmonson Point. A search for tagged birds outside of the intensive study area helped identify only a few breeders (Olmastroni, personal observation). Capture-markrecapture models used to estimate survival rates at the colony of Edmonson Point (Ballerini et al., 2009) confound permanent emigration with mortality. Thus, any bird breeding outside the intensive study area will be considered as dead and negatively bias the juvenile survival rate. To take into account this likely underestimation in survival rates in the first year (Ballerini et al., 2009), we used the time-invariant dataset to perform a fitness landscape analysis to identify the value of first-year survival that determines a population growth rate $(\lambda)$ equal to 1 . The analysis showed that, all other parameters being constant, first-year survival $s 0 c$ should be 0.71 (Figure 3 ). This value, $s 0 c=0.71$, was used to correct the formula for first-year survival (see Section Projections of Population Growth).

\section{STOCHASTIC SEA ICE FORECASTS}

SIE and SIC are highly correlated and they can affect penguins in several ways and at different spatial scales (see Ainley et al., 2010). For the population of Adélie penguins of Edmonson Point, breeding success is not correlated to large-scale sea ice variables (Ballerini, 2007), while survival is correlated to SIE anomalies (SIEA) during winter (June, July, August, and September) in the Ross Sea (Ballerini et al., 2009). SIEA are proportional anomalies in SIE, relative to the mean from 1979 to 2010 calculated over a large sector of the Ross Sea (from 150 to $230^{\circ} \mathrm{E}$ ). This includes the ice edge area where Adélie penguins from Edmonson Point are thought to overwinter in the Ross Sea (Wilson et al., 2001; Ballerini et al., 2009; Ballard et al., 2010).

Observed SIE from 1979 to 2010 were obtained from passive microwave satellite imagery provided by the National Snow and Ice data Center, using the NASA team sea ice algorithm (Cavalieri et al., 1996, http://nsidc.org/data). Forecasts of SIE from climate models were extracted from 20 models available as part of the

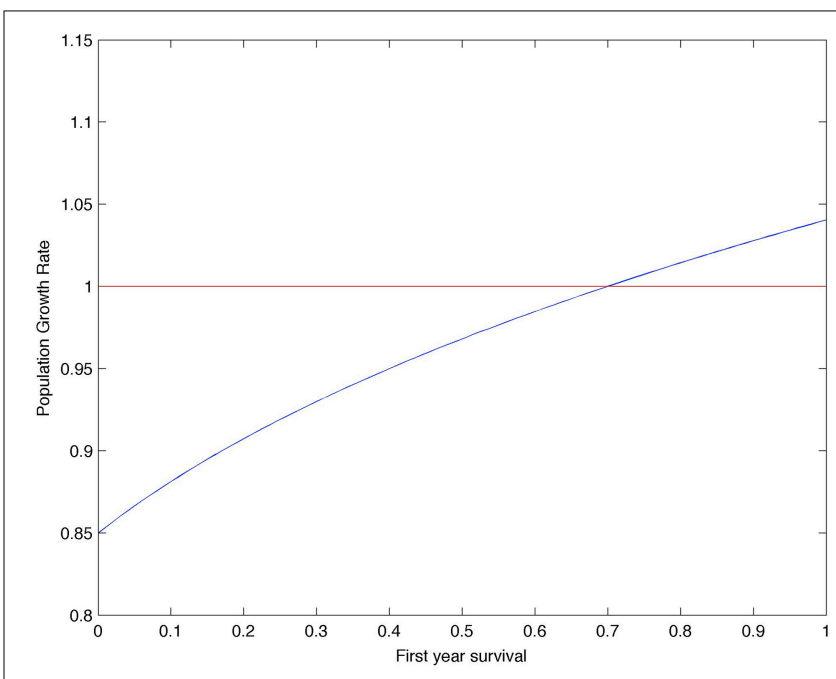

FIGURE 3 | Fitness landscape analysis. Population growth rate, $\lambda$, as a function of first-year survival, s0c. 
WCRP CMIP3 multi-model dataset from 1900 to 2100 (see Meehl et al., 2007 and http://esg.llnl.gov/portal).

AOGCMs differ in their ability to reproduce sea ice conditions in Antarctica (Lefebvre and Goosse, 2008; Ainley et al., 2010). Thus, from an initial set of 20 climate models, we selected those for which the statistical properties of the distribution of SIEA output agree well with the observations from 1979 to 2010, in terms of both the median and the standard deviation of the SIEA distribution following the approach developed by Jenouvrier et al. (2012).

The comparison of the statistical properties of the distribution of SIEA was performed for the months of June, July, August, and September. For each month, we first compared the medians, selecting model $m$ if

$$
Q_{1} \leq X_{m} \leq Q_{3}
$$

where $X_{m}$ is the median of the SIEA output of model $m$ and $Q_{1}$ and $Q_{3}$ are the first and third quartile of the distribution of observations. Second we compared the standard deviation of SIEA, selecting model $m$ if

$$
0.5^{*} s_{x o} \leq s_{x m} \leq 0.5^{*} s_{x o}
$$

where $s_{x m}$ and $s_{x o}$ are the standard deviation of SIEA from the climate model $m$ and from observations, respectively. Five models were selected for which Equations (2) and (3) applied for the 4 months. Then, we used the monthly data to create a single average value for winter SIEA and compared this value with average winter values from observations with Equations (2) and (3). The five models selected in the first phase were selected also in the second phase (Supplementary Material, Table A3).

The selected climate models were then forced with a middle range emissions scenario (SRES A1B, IPCC, 2000). This scenario assumes a future socio-economic development depending on fossil and non-fossil energy sources in balanced proportions. Under this scenario, the $\mathrm{CO}_{2}$ level doubles by 2100 , from 360 to 720 ppm.

To generate stochastic SIEA forecasts, we first obtained output for SIEA in the winter period. From this output, we computed smoothed means $x(t)$ and smoothed covariance matrices $C(t)$, using a Gaussian kernel smoother with smoothing parameter $h=2$. We then generated stochastic SIEA vectors by drawing $x(t)$ as an iid sample from a normal distribution with mean $x(t)$ and covariance matrix $C(t)$.

\section{PROJECTIONS OF POPULATION GROWTH}

We used stochastic sea ice forecasts from the IPCC models that were selected to force the survival rates in the Adélie penguin population model. Survival probabilities were expressed as a function of SIEA in the Ross Sea using the functional relationship determined for this population by Ballerini et al. (2009):

$$
\begin{aligned}
\text { Phi_age }= & \text { invlogit }\left(a l p h a \_a g e+b e t a \_a g e^{*}\right. \text { SIEA } \\
& \left.+ \text { beta_age* } \text { SIEA }^{2}\right)
\end{aligned}
$$

Where Phi_age is the survival rate for the five age classes in the population model in Figure 2, while alpha_age and beta_age are the age-specific coefficients of the relationship between survival and sea ice determined with mark-recapture models (Ballerini et al., 2009). We took into account the systematic bias in first-year survival by setting:

$$
\begin{aligned}
\text { Phi_age } 0= & \text { invlogit }\left(a l p h a \_a g e 0+b e t a \_a g e 0^{*}\right. \text { SIEA } \\
& \left.+ \text { beta_age } 0^{*} \text { SIEA }^{2}\right)+s 0 c-0.34
\end{aligned}
$$

where $s 0 c=0.71$ is the value of first-year survival derived from the fitness landscape analysis and 0.34 is the value of first-year survival, $s 0$, from the time-invariant dataset.

We projected the population under three scenarios. The first scenario considers stochastic SIE forecasts from five IPCC models to generate a sequence of demographic rates from 2010 to 2100 in the projection matrix. The initial population vector was built with the average equilibrium population structure from the timeinvariant population model. To evaluate uncertainties in climate, we used 200 stochastic forecasts from each of the five AOGCMs. The other two scenarios include SIE forecasts but also account for an increased frequency of extreme atmospheric events during the breeding season. In 2002/03, unusual strong winds and snowfall resulted in longer foraging trips during the guard stages and lead to reduced survival rates for breeders. This catastrophic breeding season was proposed to be responsible for an additional $7 \%$ in the adult mortality during the winter 2003 (Ballerini et al., 2009). Therefore, we included these extreme events by randomly sampling a matrix where adult survival, $s 4$, expressed as a function of stochastic sea ice forecasts is then depressed by $7 \%$. We considered a frequency of one catastrophic event every 14 years (as observed during the study period) for Scenario 2 and a frequency of one every other year (hypothetical scenario of an increasing frequency) for Scenario 3.

\section{RESULTS}

\section{PENGUIN POPULATION GROWTH AT EDMONSON POINT: EVALUATION} OF THE DEMOGRAPHIC MODEL

In the period 1993-2009, the Adélie penguin colony at Edmonson Point increased in size passing from 1473 to 2712 breeding pairs (Supplementary Material, Table A2). During the period 19942004 the relative size of the subcolonies that compose the colony of Edmonson Point varied strongly, some breeding groups disappeared while others increased in size. In the two subcolonies intensively studied, the number of breeding pairs decreased, ranging from 390 occupied nests in 1994 to 249 occupied nest in 2004 (Figure 4A). This corresponds to $3.1 \%$ annual decline in observed population size in the local study area. The long-term population growth rate $(\lambda)$ calculated from the time-invariant population model indicates a $6.3 \%$ annual decline of the study population, thus predicting an annual reduction in population size that is twice as much as the observed growth rate (from ground census). The $\lambda$ from the time-dependent matrix model underestimates annual population growth every year with the exception of the year from the breeding season 2000 to breeding season 2001 (Figure 4B).

\section{STOCHASTIC SEA ICE FORECASTS AND POPULATION PROJECTIONS}

Most AOGCMs projected declines in the total Antarctic SIE in the Ross Sea for the period 1979-2010 (Supplementary Material, 

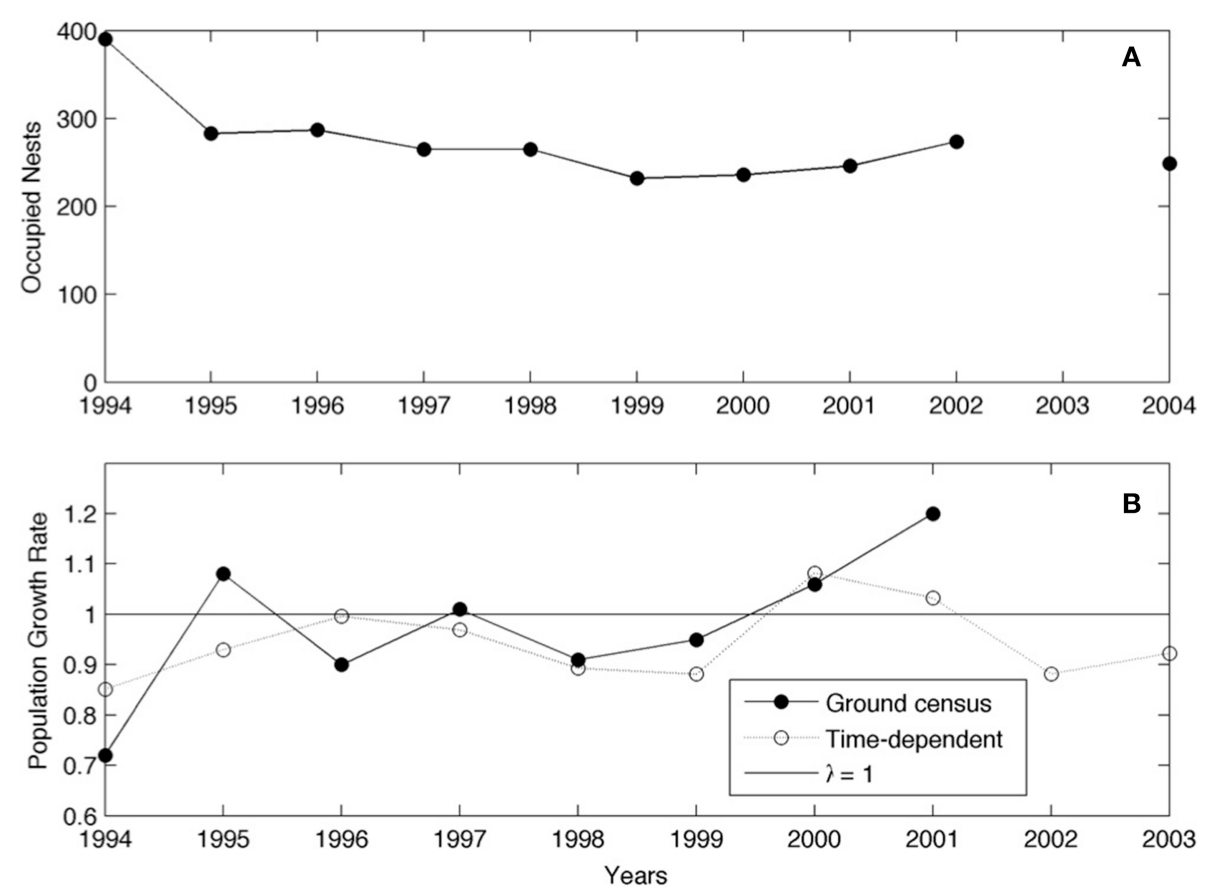

FIGURE 4 | Annual counts of population size (A) and yearly values of the population growth rate, $\lambda,(B)$ in two subcolonies at Edmonson Point. Values of $\lambda$ calculated from ground census of the breeding population (solid circles) and by the matrix population model (open circles) are indicated. Note that "breeding season 1994" indicates the breeding season 1994/95, while "winter 1995" indicates the period between the breeding season 1994 and the breeding season 1995
Figure A1), contrary to the observed trend (Stammerjohn et al., 2012). However, simulated and observed trends are generally consistent with natural variability and trend discrepancies may not necessarily indicate a model bias, especially within a short time window (Mahlstein et al., 2013; Hobbs et al., 2014). Among the 20 AOGCMs, five were retained for which the median and the standard deviation of the simulated SIEA distribution agreed with observations (Figure 5; Supplementary Material, Table A3, Figures A1, A2). The retained models are cccma-cgcm3-1-t63, giss-aom, inmcm3-0, miroc3-2-hires and gfdl_cm $2 \_0$. The last two models were also retained by Ainley et al. (2010), who predicted changes in penguin sea ice habitat around all Antarctica using several key climate variables (wind stress, Antarctic Circumpolar strength and boundary, seasonal cycle of sea ice around Antarctica and annual mean ice thickness). Differently from the first three models, these two models, miroc32-hires and gfdl_cm2_0, predict a transient increase in SIE in the Ross Sea, possibly linked to the ozone hole, before SIE decreases (Ainley et al., 2010).

The five AOGCMs that were retained were used to get stochastic SIE forecasts in the Ross Sea, which in turn were used to drive survival probability in the population projections (population projections for all the AOGCMs, including the ones that were not selected, are available in the Supplementary Material, Figure A2). All population projections from the retained AOGCMs predicted a dramatic decline of the breeding population down to extinction (Figures 6, 7; Table 1). However, there are differences in the speed of decline among the five AOGCMs. Model ccma-cgcm3-1-t63 predicts the fastest decline, with fewer than 300 breeding pairs in 30 years whereas model inmcm3-0 predicts a probability of extinction of only 0.12 after 30 years (Table 1). Model giss-aom predicts an extinction probability equal to 1 after 39 years. The two models selected also by Ainley et al. (2010), model miroc3-2hires and model gfdl_cm2_0, project a probability of extinction equal to 1 after 37 and 41 years, respectively.

When the proxy for extreme atmospheric events is included in the simulations, extinction will occur sooner (Figures 7B,C; Table 1). A catastrophic event every other year would dramatically increase the probability of extinction, which is equal to 1 in 2024 with models cccms-cgm3-1-t63 and giss-aom. Model inmcm3-0 predicts the slowest decline of the population under a scenario of one catastrophic event every 14 years but it still predicts a probability of extinction of 1 after 29 years.

\section{DISCUSSION}

By linking a population model to climate change projections, we projected that the Adélie penguin population at Edmonson Point will be functionally extinct within 40 years. Based on a qualitative analysis of penguin response to climate change projected by a set of AOGCMs, Ainley et al. (2010) predicted that 75\% of Adélie penguin colonies (70\% of breeding population) north of $70^{\circ} \mathrm{S}$ are projected to decrease or disappear when global temperature will have increased by $2^{\circ} \mathrm{C}$ above pre-industrial levels (2025-2052). Edmonson Point is located far south $\left(74^{\circ} 21^{\prime} S\right)$ and although our results are worrisome for the persistence of Adélie penguins, we have to acknowledge that the population seems to be part of a 

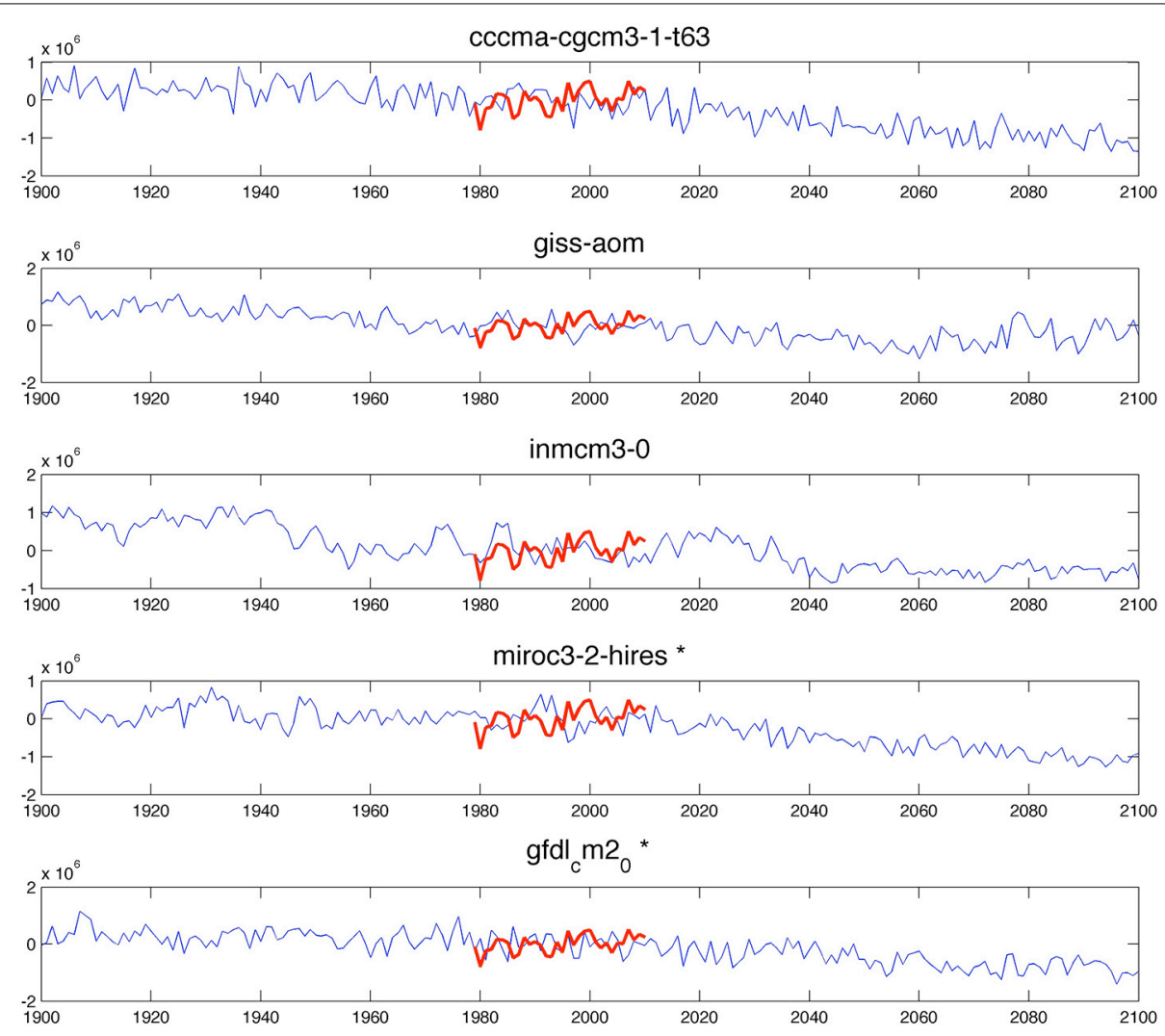

FIGURE 5 | Comparison of Ross Sea sea ice extent values derived from satellite observations (red line) and Ross Sea sea ice values derived from the AOGCMs that were retained (blue line). Models miroc3-2-hires and gfdl_cm2_0 were two of the four best models for the Ross Sea in Ainley et al. (2010).

metapopulation in which local breeding areas are connected by dispersal of breeding individuals (Ainley et al., 1995; Sheperd et al., 2005). Whether or not the metapopulation will persist is, as-yet, unknown.

\section{METAPOPULATION DYNAMICS}

Adélie penguin breeding populations all over Antarctica are organized in cluster of colonies, each cluster constituting a metapopulation with large source colonies contributing immigrants to smaller sink colonies (Ainley et al., 1995; Ainley, 2002). Dispersal rates are low among adults (1\% during average years to $3.5 \%$ under extreme environmental in southern Ross Sea, Dugger et al., 2010) while dispersal among new breeders depends on stochastic events (Sheperd et al., 2005; La Rue et al., 2013). The Terranova Bay metapopulation is composed of two large colonies, Adélie Cove and Inexpressible Island (with 11234 and 24450 breeding pairs, respectively, Lyver et al., 2014) and of the smaller colony of Edmonson Point (Ainley et al., 2005). Data on migratory rates between these colonies do not exist. However, the demographic data from Edmonson Point suggest that this colony is not a closed system (Ainley et al., 2005) and that immigration might be crucial in determining its population dynamics. Adélie penguins show a high fidelity to the breeding site and we speculate that the Edmonson Point population is composed of a pool of established breeders that come back to breed at the colony year after year, and of a pool of new breeders that immigrate from nearby colonies each year. New breeders would come from the larger colonies of the Terranova Bay metapopulation where space for breeding is limited and/or where summer competition for food can be high (Ainley et al., 2004). It is possible that the colony of Edmonson Point is sustained also by birds from colonies further south in the Ross Sea. In the breeding season 2014, in fact, five birds marked with flipper bands at Cape Royds and Cape Bird, Ross Island, were observed breeding at Edmonson Point (Olmastroni, personal observation). Immigration of new breeders from nearby colonies could explain why the colony of Edmonson Point increased in size during the study period (Lyver et al., 2014; this work) even if breeding success and first-year survival were low in comparison to other locations in the Ross Sea (Pezzo et al., 2007) and not enough to sustain population growth.

Sink populations are usually situated in low quality habitats (Pulliam, 1988). Extensive fast ice (about $20 \mathrm{~km}$ ) rests in place in front of Edmonson Point almost every year (Olmastroni et al., personal observation), thus making it energetically more costly for penguins to search for food, as they are obliged to walk instead of swimming to reach their foraging grounds (Clarke et al., 1998; Olmastroni, 2002). Longer foraging trips might cause lower delivery rates of food to chicks, thus negatively impacting the breeding success (Clarke et al., 2002; Olmastroni et al., 2004b). Delivery rates to chicks might also be limited by food competition with Adélies from the other colonies of the Terranova Bay metapopulation and with emperor penguins from the nearby colony of 


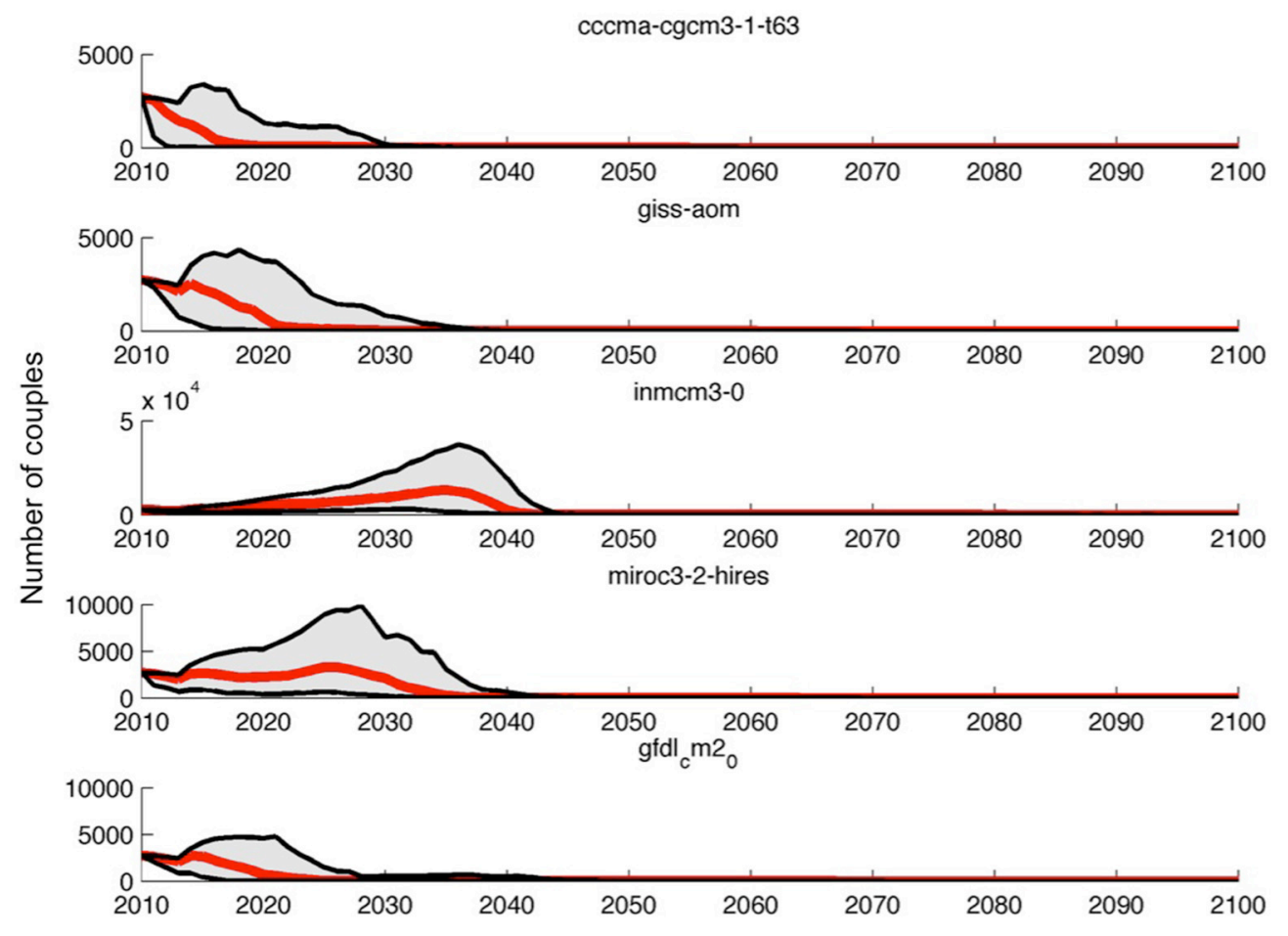

FIGURE 6 | Projections of the Adélie penguin population at Edmonson Point based on stochastic sea ice extent anomalies forecasts from five

AOGCMs. For each AOGCM, the median population trajectory (thick red line) and the $95 \%$ envelope (gray area), from 200 stochastic simulations are shown.

Cape Washington (almost 12000 breeding pairs, Barber-Meyer et al., 2007; but see Ainley et al., 1995). Finally, breeding success is strongly limited at Edmonson Point by predation of eggs and chicks by the South polar skua (Catharacta maccormicki). With a ratio skua pairs/penguins pairs of 1:20, the highest recorded along the Victoria Land coast (Pezzo et al., 2001), about 52\% of eggs and chicks are predated each year (Olmastroni and Pezzo, unpublished data, average over 5 years).

The population growth rate calculated from the matrix population model is negative almost every year, indicating that the colony is not self-sustaining. While adult survival measured at Edmonson Point (Ballerini et al., 2009) is in the range of variability of other Adélie penguin populations that are not declining (cfr. Jenouvrier et al., 2006; Lescroël et al., 2009; Emmerson and Southwell, 2011), apparent juvenile survival (Ballerini et al., 2009; Emmerson and Southwell, 2011) and breeding success are lower than in other populations (Ainley, 2002 and studies herein; Pezzo et al., 2007). For these reasons, we speculate that the colony of Edmonson Point is a sink population sustained by neighboring colonies, and that the estimates of juvenile survival might be biased. Indeed, dispersal may be limited among adults but may be higher among juveniles ( $\mathrm{La}$ Rue et al., 2013). Therefore, to project population response, we corrected for this systematic bias by tuning our population model so that the growth rate projected during the observation period matches a stable population (see fitness landscape analysis). Model tuning is a common strategy in climate modeling, so that the properties of climate models are adjusted in various ways to best match the known state of the
Earth's climate system. Typically, the tuning is performed over uncertain and non-observable parameters related to processes not explicitly represented in the models (Mauritsen et al., 2012).

\section{POPULATION PROJECTIONS}

The population of Edmonson Point is projected to decline at a rapid rate, especially if extreme snow events are accounted for. The population is projected to be functionally extinct as soon as 13 years and as late as 40 years, depending on the climate models used to project SIE and on the frequency of simulated extreme weather events at breeding.

Differences among models in the SIE simulation outputs are due to uncertainties in the representation of climate processes within the models (Lefebvre and Goosse, 2008; Turner et al., 2013). In order to account for this structural uncertainty, we selected a model subset by comparing climatological aspects of the simulated SIEA to the observed climatology in term of median and standard deviation of the SIEA distributions during the study period (Jenouvrier et al., 2012; Jenouvrier, 2013; Jenouvrier et al., 2014). Because the climate variable included in our population model is SIEA and our aim is to project population trajectories given future SIEA projections, we believe this is a robust approach.

When using SIE forecasts from the five AOGCMs, all simulations of population dynamics predict extinction of the population of Edmonson Point in the next 40 years. However, different climate models imply different future sea-ice projections. For example, model miroc3-2-hires and model gfdl_cm2_0 predict a 

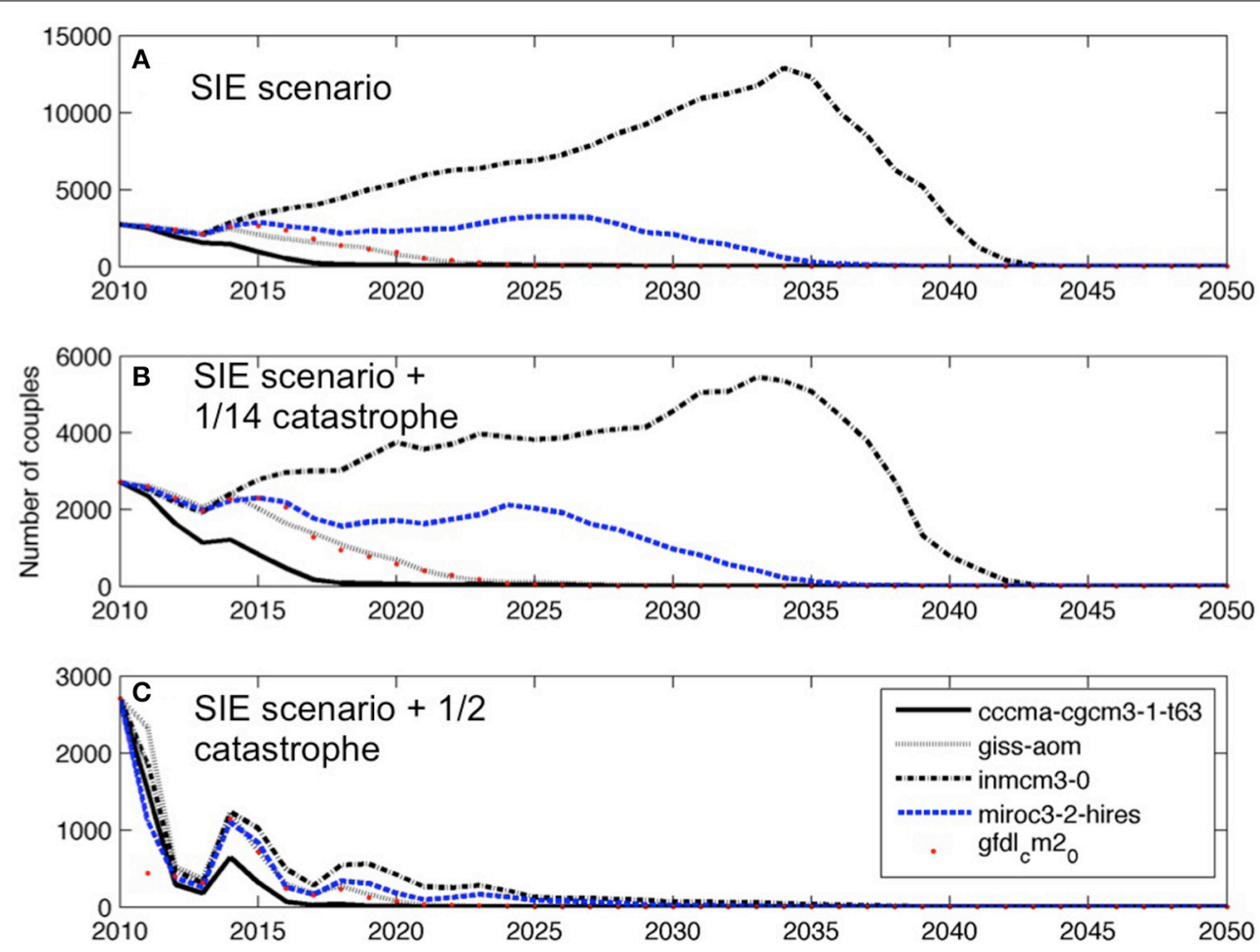

FIGURE 7 | Projections of the Adélie penguin population at Edmonson Point based on stochastic sea ice extent anomalies forecasts from five AOGCMs (A), considering a catastrophic weather event at breeding with a frequency of 1 over 14 years (B), and considering a catastrophic weather event every other year $(\mathbf{C})$. For each AOGCM, the median population trajectory from 200 stochastic simulations is shown. temporary increase in SIE in the Ross Sea in the next decades, although a general decrease in the long run. A temporary increase in winter sea ice implies a displacement further north of the ice edge, which is thought to negatively impact juvenile survival over the winter period by reducing the access to food resources (Wilson et al., 2001). For a similar reason, extreme winter SIE is also associated with reduced adult survival (Ballerini et al., 2009). All AOGCMs agree in predicting a decline of SIE by the mid of this century (Ainley et al., 2010). Reduced SIE means a displacement toward the south of the ice edge, possibly at latitudes where there is no light in the winter. This can impact over-winter survival by increasing competition for the narrow suitable winter habitat with enough light for penguins to successfully forage (Ballard et al., 2010).

Adélie penguins from Edmonson Point most likely share the same wintering grounds as birds from the other colonies along Victoria Land (Wilson et al., 2001; Ballard et al., 2010). Since survival in the Adélie penguin is affected by winter SIE and SIC (Wilson et al., 2001; Jenouvrier et al., 2006; Ballerini et al., 2009), it is likely that changes in SIE will affect survival rates of penguins from Adélie Cove and Inexpressible Island too. If this hypothesis is true, survival rates of penguins from other colonies will likely decline because sea ice is projected to shrink everywhere in Antarctica (Ainley et al., 2010). This can affect the immigration fluxes toward Edmonson Point and the persistence of the metapopulation in the Ross Sea. Future work entails projecting Adélie penguin population responses throughout the entire species range, by including dispersal scenarios and different functional relationships between climate and demography along a latitudinal gradient (Jenouvrier et al., 2014).

The responses of seabird populations to large-scale environmental changes will depend on the sensitivity of their demographic parameters to the physical processes and on how the changes in demographic parameters are expressed at the population level ( $\AA$ dahl et al., 2006). Since survival has a strong impact on population growth, the expected reduction in SIE and increase in snowfall are likely to negatively impact the population dynamics of Edmonson Point. According to the matrix population model, these changes in the physical environment will determine an increase in the speed of decline of the population of Edmonson Point. The ability of Adélie penguins to respond to global environmental changes will depend on their ability to modulate the breeding strategy in the summer and on the availability of suitable habitat in the winter (cfr. Ainley et al., 2010).

The plastic responses of Adélie penguins to the their changing environment are being increasingly studied (Lynch et al., 2012; La Rue et al., 2013; Dugger et al., 2014; Lescroël et al., 2014). While it has been found that Adélie penguins can adapt their foraging efficiency to abrupt changes in SIC during the summer period (Lescroël et al., 2014), it is less clear how much they can modify their breeding phenology and breeding strategy (Barbraud and Weimerskirch, 2006; Dugger et al., 2010, 2014; Lynch et al., 2012). Adélie penguins are long-range migrant species that evolved their breeding strategy in response to an environment that varied over 
Table 1 | Probability of extinction of the Adélie penguin population of Edmonson Point at time $t=10,20,30$, and 40 years after 2010, for five AOGCMs and three environmental scenarios.

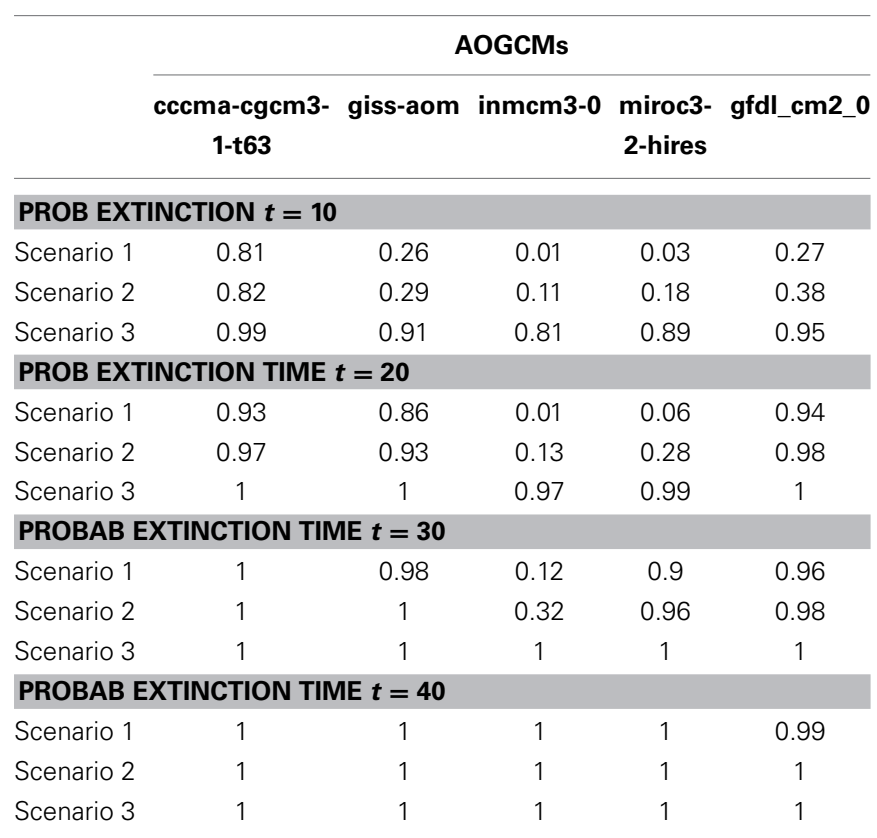

Scenario, stochastic sea ice; scenario 2 = stochastic sea ice + proxy snowfall every 14 years; scenario 3 = stochastic sea ice + proxy snowfall every other year (see the Methods Section for more details).

much longer geological time scales than the current temporal scale of climate change (Fraser and Trivelpiece, 1996; Emslie et al., 2007; Forcada et al., 2008; Thatje et al., 2008; Li et al., 2014). AOGCMs predict an increased probability of extreme atmospheric events (Ainley et al., 2010), such as the heavy snowstorm that caused extensive mortality of eggs and chicks in 2003 (Olmastroni et al., 2004a). The possibility of microevolutionary adaptive responses (Sheperd et al., 2005) is probably limited in species with a long generation time (Rosenheim and Tabashnik, 1991) such as the Adélie penguin. In these species, the maximization of fitness is likely to rely on phenotypic plasticity or shortterm individual responses to the environment (Forcada et al., 2008). If the frequency of "catastrophic" climatic events at Adélie penguin breeding sites increases and happens in a time interval equal to the generation time, there will not be a generation with a high fitness and the population will go extinct (Forcada et al., 2008; Melbourne and Hastings, 2008). So the responses of Adélie penguins to changing environment will depend, in part, on their ability to change their breeding phenology and breeding strategy.

Possible future changes in the Ross Sea food web (Smith et al., 2007, 2014), could potentially exacerbate the direct effects of changes in habitat availability on the viability of Adélie penguins populations. The principal prey species for Adélie penguins, krill and Antarctic silverfish, depend on the sea ice for successful completion of their life cycles. Disappearance of prey species in response to reduced sea ice habitat is thought to be one of the causes of reduction of penguin populations in the western Antarctic Peninsula region (Schofield et al., 2010; Trivelpiece et al., 2011; Sailley et al., 2013). Understanding the effects of climate change is further complicated by alterations to the Antarctic food web due to harvesting activities (Trivelpiece et al., 2011; Lyver et al., 2014). Lyver et al. (2014) suggest that the rapid increase in population size in the southern colonies of the Ross Sea since 2001 was, at least in part, due to competitive release of Antarctic silverfish following the commercial removal of the Antarctic toothfish (Dissostichus mawsoni).

As a conclusion, we detected and quantified the actual and future decrease of a small Adélie penguin colony that is probably part of a larger metapopulation. We concluded that this colony is a sink population, not limited by breeding sites availability but by inter-specific processes such as high predation. This population is sustained by immigration from larger colonies of the metapopulation. A decreasing trend of such sink population might be seen as a "spy light" indicating a possible future decrease of the whole metapopulation, including the source colonies. Causes of this potential general decline have to be investigated both among global drivers affecting adult survival, such as sea ice conditions over large areas, and among local drivers, such as stochastic weather events, greatly affecting breeding success.

\section{ACKNOWLEDGMENTS}

This work was supported by the Italian Antarctic Research Program (PNRA) and by the Italian Ministry for University and Research (MIUR). The Australian Antarctic Division (AAD) provided the Automatic Penguin Monitoring System (APMS) used in the mark-recapture study. We are very grateful to Prof. Silvano Focardi and Dr. Knowles Kerry, former scientific leaders, and to the many people from the Department of Environmental Sciences of the University of Siena and from the AAD who were actively involved in field data collection over many years. We would like to thank Valerio Volpi who produced the map in Figure 1. Tosca Ballerini was supported by a doctoral fellowship in Polar Science 2003-2006, University of Siena. Stephanie Jenouvrier acknowledges support from the Grayce B. Kerr Fund and the Penzance Endowed Fund in Support of Assistant Scientists and Grant ANT0944411. We acknowledge the modeling groups, the Program for Climate Model Diagnosis and Intercomparison (PCMDI) and the Working Group on Coupled Modeling (WGCM) of the World Climate Research Program (WCRP) for sea ice data. We thank the two reviewers for their input and constructive criticism, which greatly helped to improve the quality of the manuscript. This research was designed and coordinated by Francesco Pezzo, Giacomo Tavecchia and Silvia Olmastroni. Francesco Pezzo conceived the population study and its design, built the research team, collected field data (since 1998), contributed to the interpretation of the results and provided critical revision of the manuscript. Giacomo Tavecchia designed the population analysis, contributed to the interpretation of results and provided critical revision of the ms. Stephanie Jenouvrier performed the sea ice data analysis, provided the computing code and assisted with the sea ice dependent population analysis, helped in the interpretation of the results and provided critical revision of the manuscript. Silvia Olmastroni collected field data since 1996, managed and provided the Edmonson Point dataset, performed analysis and interpretation of breeding population ground census data, and provided critical revision of the manuscript. Tosca Ballerini collected field data in 2004, coordinated and performed the analysis, wrote the manuscript. All 
authors revised the final manuscript and agreed to be accountable for it.

\section{SUPPLEMENTARY MATERIAL}

The Supplementary Material for this article can be found online at: http://www.frontiersin.org/journal/10.3389/fevo.2015. 00008/abstract

\section{REFERENCES}

Ådahl, E., Lundberg, P., and Jonzén, N. (2006). From climate change to population change: the need to consider annual life cycles. Glob. Change Biol. 12, 1627-1633. doi: 10.1111/j.1365-2486.2006.01196.x

Ainley, D. G. (2002). The Adélie Penguin. Bellwether of Climate Change. New York, NY: Columbia University Press.

Ainley, D. G., Clarke, E. D., Arrigo, K. R., Fraser, W. R., Kato, A., Barton, K. J., et al. (2005). Decadal-scale changes in the climate and biota of the Pacific sector of the Southern Ocean, 1950s to 1990s. Antarct. Sci. 17, 171-182. doi: $10.1017 /$ S0954102005002567

Ainley, D. G., Nadav, N., and Woehler, E. J. (1995). Factors affecting the distribution and size of pygoscelid penguin colonies in the Antarctic. Auk 112, 171-182.

Ainley, D. G., Ribic, C. A., Ballard, G., Heath, S., Gaffney, I., Karl, B. J., et al. (2004). Geographic structure of Adélie penguin populations: overlap in colony-specific foraging areas. Ecol. Monogr. 74, 159-178. doi: 10.1890/02-4073

Ainley, D. G., Russell, J., Jenouvrier, S., Woehler, E., Lyver, P. O’B., Fraser, W. R., et al. (2010). Antarctic penguin response to habitat change as Earth's troposphere reaches $2^{\circ} \mathrm{C}$ above preindustrial levels. Ecol. Monogr. 80, 49-66. doi: $10.1890 / 08-2289.1$

Ballard, G., Toniolo, V., Ainley, D. G., Parkinson, C. L., Arrigo, K. R., and Trathan, P. N. (2010). Responding to climate change: Adélie Penguins confront astronomical and ocean boundaries. Ecology 91, 2056-2069. doi: 10.1890/09-0688.1

Ballerini, T. (2007). From Individual Information to Population models: the Case of a Long Lived Antarctic Species, the Adélie Penguin Pygoscelis Adeliae. Ph.D. thesis (in Italian), University of Siena, Siena, 100.

Ballerini, T., Tavecchia, G., Olmastroni, S., Pezzo, F., and Focardi, S. (2009). Nonlinear effects of winter sea ice on the survival probabilities of Adélie penguins. Oecologia 161, 253-265. doi: 10.1007/s00442-009-1387-9

Barber-Meyer, S. M., Kooyman, G. L., and Ponganis, P. J. (2007). Estimating the relative abundance of emperor penguins at inaccessible colonies using satellite imagery. Polar Biol. 30, 1565-1570. doi: 10.1007/s00300-007-0317-8

Barbraud, C., and Weimerskirch, H. (2006). Antarctic birds breed later in response to climate change. Proc. Natl. Acad. Sci. U.S.A. 103, 6248-6251. doi: 10.1073/pnas.0510397103

Baroni, C., and Orombelli, G. (1994). Abandoned penguin rookeries as Holocene paleoclimatic indicators in Antarctica. Geology 22, 23-26.

Caswell, H. (2001). Matrix Population Models: Construction, Analysis, and Interpretation. Sunderland, MA: Sinauer Associates.

Cavalieri, D., Parkinson, C., Gloersen, P., and Zwally, H. J. (1996). Sea Ice Concentrations From Nimbus-7 Smmr and Dmsp ssm/i Passive Microwave Data. Boulder, CO: National Snow and Ice Data Center. Digital media.

Cavalieri, D. J., Parkinson, C. L., and Vinnikov, K. Y. (2003). 30-year satellite record reveals contrasting Arctic and Antarctic decadal sea ice variability. Geophys. Res. Lett. 18, 1970. doi: 10.1029/2003GL018031

Clarke, J., Kerry, K., Irvine, L., and Phillips, B. (2002). Chick provisioning and breeding success of Adélie penguins at Bechervaise Island in eight successive seasons. Polar Biol. 25, 21-30. doi: 10.1007/s003000100307

Clarke, J., Manly, B., Kerry, K., Gardner, H., Franchi, E., and Focardi, S. (1998). Sex differences in Adélie penguin foraging strategies. Polar Biol. 20, 248-258. doi: $10.1007 / \mathrm{s} 003000050301$

Croxall, J., Trathan, P., and Murphy, E. (2002). Environmental change and Antarctic seabirds populations. Science 297, 1510-1514. doi: 10.1126/science.1071987

Ducklow, H. W., Baker, K., Martinson, D. G., Quetin, L. B., Ross, R. M., Smith, R. C., et al. (2007). Marine pelagic ecosystems: the West Antarctic Peninsula. Philos. Trans. R. Soc. B Biol. Sci. 362, 67-94. doi: 10.1098/rstb.2006.1955

Dugger, K. M., Ainley, D. G., Lyver, P. O. B., Barton, K., and Ballard, G. (2010). Survival differences and the effect of environmental instability on breeding dispersal in an Adélie penguin metapopulation. Proc. Natl. Acad. Sci. U.S.A. 107, 12375-12380. doi: 10.1073/pnas.1000623107

Dugger, K. M., Ballard, G., Ainley, D. G., Lyver, P. O. B., and Schine, C. (2014). Adélie penguins coping with environmental change: results from a natural experiment at the edge of their breeding range. Front. Ecol. Evol. 2:68. doi: $10.3389 /$ fevo. 2014.00068

Emmerson, L., and Southwell, C. (2008). Sea ice cover and its influence on Adélie penguin reproductive performance. Ecology 89, 2096-2102. doi: 10.1890/080011.1

Emmerson, L., and Southwell, C. (2011). Adélie penguin survival: age structure, temporal variability and environmental influences. Oecologia 167, 951-965. doi: 10.1007/s00442-011-2044-7

Emslie, S. D., Coats, L., and Licht, K. (2007). A 45000-year record of Adélie Penguins and climate change in the Ross Sea, Antarctica. Geology 35, 61-64. doi: $10.1130 /$ G23011A.1

Forcada, J., and Trathan, P. N. (2009). Penguin responses to climate change in the Southern Ocean. Glob. Change Biol. 15, 1618-1630. doi: 10.1111/j.13652486.2009.01909.x

Forcada, J., Trathan, P. N., and Murphy, E. J. (2008). Life history buffering in Antarctic mammals and birds against changing patterns of climate and environmental variation. Glob. Change Biol. 14, 2473-2488. doi: 10.1111/j.13652486.2008.01678.x

Forcada, J., Trathan, P. N., Reid, K., Murphy, E. J., and Croxall, J. P. (2006). Contrasting population changes in sympatric penguin species in association with climate warming. Glob. Change Biol. 12, 411-423. doi: 10.1111/j.13652486.2006.01108.x

Fraser, W. R., and Trivelpiece, W. Z. (1996). "Factors controlling the distribution of seabirds: winter-summer heterogeneity in the distribution of Adélie penguin populations" in Foundations for Ecological Research West of the Antarctic Peninsula, Vol. 70, eds R. M. Ross, E. E. Hofmann, and L. B. Quetin (Washington, DC: American Geophysical Union), 257-272. doi: 10.1029/ AR070p0257

Fraser, W. R., Trivelpiece, W. Z., Ainley, D. G., and Trivelpiece, S. G. (1992). Increases in Antarctic penguin populations: reduced competition with whales or a loss of sea ice due to environmental warming? Polar Biol. 11, 525-531.

Hinke, J. T., Salwicka, K., Trivelpiece, S. G., Watters, G. M., and Trivelpiece, W. Z. (2007). Divergent responses of Pygoscelis penguins reveal a common environmental driver. Oecologia, 153, 845-855. doi: 10.1007/s00442-007-0781-4

Hobbs, W., Bindoff, N. L., and Raphael, M. N. (2014). New perspectives on observed and simulated late Antarctic sea ice extent trends using optima fingerprinting techniques. J. Climate. doi: 10.1175/JCLI-D-14-00367.1. [Epub ahed of print].

Jenouvrier, S. (2013). Impacts of climate change on avian populations. Glob. Change Biol. 19, 2036-2057. doi: 10.1111/gcb.12195

Jenouvrier, S., Barbraud, C., and Weimerkirch, H. (2005). Long-term contrasted responses to climate of two Antarctic seabird species. Ecology 86, 2889-2903. doi: 10.1890/05-0514

Jenouvrier, S., Barbraud, C., and Weimerskirch, H. (2006). Sea ice affects the population dynamics of Adélie penguins in Terre Adélie. Polar Biol. 29, 413-423. doi: 10.1007/s00300-005-0073-6

Jenouvrier, S., Caswell, H., Barbraud, C., Holland, M., Stroeve, J., and Weimerskirch, H. (2009). Demographic models and IPCC climate projections predict the decline of an emperor penguin population. Proc. Natl. Acad. Sci. U.S.A. 106, 1844-1847. doi: 10.1073/pnas.0806638106

Jenouvrier, S., Holland, M., Stroeve, M., Barbraud, C., Weimerskirch, H., and Caswell, H. (2014). Projected continent-wide declines of the emperor penguin under climate change. Nat. Clim. Change 4, 715-718. doi: 10.1038/nclimate2280

Jenouvrier, S., Holland, M., Stroeve, J., Barbraud, C., Weimerskirch, H., Serreze, M., et al. (2012). Effects of climate change on an emperor penguin population: analysis of coupled demographic and climate models. Glob. Change Biol. 18, 2756-2770. doi: 10.1111/j.1365-2486.2012.02744.x

Kwok, R., and Comiso, J. C. (2002). Southern ocean climate and sea ice anomalies associated with the southern oscillation. J. Clim. 15, 487-501. doi: 10.1175/1520-0442(2002)015<0487:SOCASI > 2.0.CO;2

La Rue, M. A., Ainley, D. G., Swanson, M., Dugger, K. M., Lyver, P. O. B., Barton, K., et al. (2013). Climate change winners: receding ice fields facilitate colony expansion and altered dynamics in an Adélie penguin metapopulation. PLoS ONE 8:e60568. doi: 10.1371/journal.pone.0060568

Lefebvre, W., and Goosse, H. (2008). Analysis of the projected regional sea ice changes in the Southern Ocean during the 21st century. Clim. Dyn. 30, 59-76. doi: 10.1007/s00382-007-0273-6

Lescroël, A., Ballard, G., Grémillet, D., Authier, M., and Ainley, D. G. (2014). Antarctic climate change: extreme events disrupt plastic phenotypic response in Adélie penguins. PLoS ONE 9:e85291. doi: 10.1371/journal.pone.0085291 
Lescroël, A., Dugger, K. M., Ballard, G., and Ainley, D. G. (2009). Effects of individual quality, reproductive success and environmental variability on survival of a long-lived seabird. J. Anim. Ecol. 78, 798-806. doi: 10.1111/j.13652656.2009.01542.x

Li, C., Zhang, Y., Li, J., Kong, L., Hu, H., Pan, H., et al. (2014). Two Antarctic penguin genomes reveal insights into their evolutionary history and molecular changes related to the Antarctic environment. GigaScience 3:27. doi: 10.1186/ 2047-217X-3-27

Lynch, H. J., Naveev, R., Trathan, P. N., and Fagan, W. F. (2012). Spatially integrated assessment reveals widespread changes in penguin populations on the Antarctic Peninsula. Ecology 93, 1367-1377. doi: 10.1890/11-1588.1

Lyver, P. O’B., Barron, M., Barton, K. J., Ainley, D. G., Pollard, A., Gordon, S., et al. (2014). Trends in the breeding population of Adélie penguins in the Ross Sea, 1981-2012: a coincidence of climate and resource extraction effects. PLoS ONE 9:e91188. doi: 10.1371/journal.pone.0091188

Mahlstein, I., Gent, P. R., and Solomon, S. (2013). Historical Antarctic mean sea ice area, sea ice trends, and winds in CMIP5 simulations. J. Geophys. Res. 118, 5105-5110. doi: 10.1002/jgrd.50443

Mauritsen, T., Stevens, B., Roeckner, E., Crueger, T., Esch, M., Giorgetta, M., et al. (2012). Tuning the climate of a global model. J. Adv. Model. Earth Syst. 4, M00A01. doi: 10.1029/2012MS000154

Meehl, G. A., Covey, C., Taylor, K. E., Delworth, T., Stouffer, R. J., Latif, M., et al. (2007). The wcrp cmip3 multi-model dataset: a new era in climate change research. Bull. Am. Meteorol. Soc. 88, 1383-1394. doi: 10.1175/BAMS-88-9-1383

Melbourne, B. A., and Hastings, A. (2008). Extinction risk depends strongly on factors contributing to stochasticity. Nature 454, 100-103. doi: 10.1038 /nature 06922

Oli, M. K. (2014). Biodiversity: Penguins in peril. Nat Clim. Change, 4, 667-668. doi: $10.1038 /$ nclimate 2328

Olmastroni, S. (2002). Factors Affecting the Foraging Strategies of Adélie Penguin (Pygoscelis adeliae) at Edmonson Point, Ross Sea, Antarctica. Ph.D. thesis, University of Siena. doi: 10.1130/G23011A.1

Olmastroni, S., Corsolini, S., Pezzo, F., Focardi, S., and Kerry, K. (2000). The first five years of the Italian-Australian joint programme on the Adélie penguin: an overview. Ital. J. Zool. 67, 141-145. doi: 10.1080/11250000009356369

Olmastroni, S., Pezzo, F., Bisogno, I., and Focardi, S. (2004b). Interannual Variation in the Summer diet of Adélie Penguin (Pygoscelis adeliae) at Edmonson Point. CCAMLR Working Group on Ecosystem Monitoring and Management, WGEMM 04/38.

Olmastroni, S., Pezzo, F., Volpi, V., and Focardi, S. (2004a). Effects of weather and sea ice on the reproductive performance of the Adélie penguin at Edmonson Point. CCAMLR Sci. 11, 99-109. Available online at: https://www.ccamlr.org/en/publications/science_journal/ccamlr-sciencevolume-11/ccamlr-science-volume-1199-109

Parkinson, C. L. (2002). Trends in the length of the Southern Ocean sea ice season, 1979-99. Ann. Glaciol. 34, 435-440. doi: 10.3189/172756402781817482

Pezzo, F., Olmastroni, S., Corsolini, S., and Focardi, S. (2001). Factors affecting the breedig success of the south polar skua Catharacta maccormicki at Edmonson Point, Victoria Land, Antarctica. Polar Biol. 24, 389-393. doi: 10.1007/s003000000213

Pezzo, F., Olmastroni, S., Volpi, V., and Focardi, S. (2007). Annual variation in reproductive parameters of Adélie penguins at Edmonson Point, Victoria Land, Antarctica. Polar Biol. 31, 39-45. doi: 10.1007/s00300-007-0330-y

Pulliam, H. R. (1988). Sources, sinks and population regulation. Am. Nat. 132, 652-661.

Rosenheim, J. A., and Tabashnik, B. E. (1991). Influence of generation time on the rate of response to selection. Am. Nat. 137, 527-541.

Sailley, F. S., Ducklow, H. W., Moeller, H. V., Fraser, W. R., Schofield, O. M., Steinberg, D. K., et al. (2013). Carbon fluxes and pelagic ecosystem dynamics near two western Antarctic Peninsula Adélie penguin colonies: an inverse modelling approach. Mar. Ecol. Prog. Ser. 492, 253-272. doi: 10.3354/meps 10534

SC-CCAMLR. (2004). CCAMLR Ecosystem Monitoring Program: Standard Methods. Hobart, TAS: Tasmania.

Schofield, O., Ducklow, H. W., Martinson, D. G., Meredith, M. P., Moline, M. A., and Fraser, W. R. (2010). How do polar marine ecosystems respond to rapid climate change? Science 328, 1520-1523. doi: 10.1126/science.1185779

Sheperd, L. D., Millar, C. D., Ballard, G. D. G., Ainley, P. R., Wilson, G. D., Haynes, C., et al. (2005). Microevolution and mega-icebergs in the
Antarctic. Proc. Natl. Acad. Sci. U.S.A. 102, 16717-16722. doi: 10.1073/pnas. 0502281102

Siniff, D. B., Garrott, R. A., Rotella, J. J., Fraser, W. R., and Ainley, D. G. (2008). Opinion: projecting the effects of environmental change on Antarctic seals. Antarct. Sci. 20, 425-435. doi: 10.1017/S0954102008001351

Smith, R. C., Ainley, D., Baker, K., Domack, E., Emslie, S., Fraser, B., et al. (1999). Marine Ecosystem sensitivity to climate change. Bioscience 49, 393-404.

Smith, R. C., Ainley, D. G., and Cattaneo-Vietti, R. (2007). Trophic interactions within the Ross Sea continental shelf ecosystem. Philos. Trans. R. Soc. Lond. B Biol. Sci. 362, 95-111. doi: 10.1098/rstb.2006.1956

Smith, W. O., Dinniman, M. S., Hofmann, E. E., and Klinck, J. M. (2014). The effects of changing winds and temperatures on the oceanography of the Ross Sea in the 21st century. Geophys. Res. Lett. 41, 1624-1631. doi: 10.1002/2014GL059311

Stammerjohn, S. E., Martinson, D. G., Smith, R. C., and Iannuzzi, R. A. (2008). Sea ice in the western Antarctic Peninsula region: spatio-temporal variability from ecological and climate change perspectives. Deep Sea Res. Part II Top. Stud. Oceanogr. 55, 2041-2058. doi: 10.1016/j.dsr2.2008.04.026

Stammerjohn, S. E., Massom, R., Rind, D., and Martinson, D. (2012). Regions of rapid sea ice change: an inter-hemispheric seasonal comparison. Geophys. Res. Lett. 39, L06501. doi: 10.1029/2012GL050874

Thatje, S., Hillenbrand, C. D., Mackensen, A., and Larter, R. (2008). Life hung by a thread: endurance of Antarctic fauna in Glacial periods. Ecology 89, 682-692. doi: 10.1890/07-0498.1

Trivelpiece, W. Z., and Fraser, W. R. (1996). "The breeding biology and distribution of Adélie penguins: adaptation to environmental variability," in Foundation for Ecological Research West of Antarctic Peninsula. Antarctic Research Series, Vol. 70, eds R. M. Ross, E. E. Hofmann, and L. B. Quetin (Washington, DC: American Geophysical Union), 273-285. doi: 10.1029/ AR070p0273

Trivelpiece, W. Z., Hinke, J. T., Miller, A. K., Reiss, C. S., Trivelpiece, S. G., and Watters, G. M. (2011). Variability in krill biomass links harvesting and climate warming to penguin population changes in Antarctica. Proc. Natl. Acad. Sci. U.S.A. 108, 7625-7628. doi: 10.1073/pnas.1016560108

Turner, J., Bindschadler, R. A., Convey, P., Di Prisco, G., Fahrbach, E., Gutt, J., et al. (2009). Antarctic Climate Change and the Environment. Cambridge, SCAR.

Turner, J., Bracegirdle, T. J., Phillips, T., Marshall, G. J., and Hosking, J. S. (2013). An initial assessment of Antarctic sea ice extent in the CMIP5 models. J. Climate 26, 1473-1484. doi: 10.1175/JCLI-D-12-00068.1

Ward, D. H., Reed, A., Sedinger, J. S., Black, J. M., Derksen, D. V., and Castelli, P. M. (2005). North American brant: effects of changes in habitat and climate on population dynamics. Glob. Chang. Biol. 11, 869-880. doi: 10.1111/j.13652486.2005.00942.x

Wilson, P. R., Ainley, D. G., Nur, N., Jacobs, S. S., Barton, K. J., Ballard, G., et al. (2001). Adélie penguin population change in the pacific sector of Antarctica: relation to sea ice extent and the Antarctic Circumpolar Current. Mar. Ecol. Prog. Ser. 213, 301-309. doi: 10.3354/meps213301

Zwally, H. J., Comiso, J. C., Parkinson, C. L., Cavalieri, D. J., and Gloersen, P. (2002). Variability of Antarctic sea ice 1979-1998. J. Geophys. Res. 107, 3041-3049. doi: 10.1130/G23011A.1

Conflict of Interest Statement: The authors declare that the research was conducted in the absence of any commercial or financial relationships that could be construed as a potential conflict of interest.

Received: 04 November 2014; accepted: 16 January 2015; published online: 13 February 2015.

Citation: Ballerini T, Tavecchia G, Pezzo F, Jenouvrier S and Olmastroni S (2015) Predicting responses of the Adélie penguin population of Edmonson Point to future sea ice changes in the Ross Sea. Front. Ecol. Evol. 3:8. doi: 10.3389/fevo.2015.00008

This article was submitted to Interdisciplinary Climate Studies, a section of the journal Frontiers in Ecology and Evolution.

Copyright (C) 2015 Ballerini, Tavecchia, Pezzo, Jenouvrier and Olmastroni. This is an open-access article distributed under the terms of the Creative Commons Attribution License (CC BY). The use, distribution or reproduction in other forums is permitted, provided the original author(s) or licensor are credited and that the original publication in this journal is cited, in accordance with accepted academic practice. No use, distribution or reproduction is permitted which does not comply with these terms. 